\title{
Empowering young people and strengthening resilience: youth-centred participatory video as a tool for climate change adaptation and disaster risk reduction
}

\section{Katharine Haynes \& Thomas M. Tanner}

To cite this article: Katharine Haynes \& Thomas M. Tanner (2015) Empowering young people and strengthening resilience: youth-centred participatory video as a tool for climate change adaptation and disaster risk reduction, Children's Geographies, 13:3, 357-371, DOI: 10.1080/14733285.2013.848599

To link to this article: https://doi.org/10.1080/14733285.2013.848599

$$
\text { () } 2013 \text { The Author(s). Published by Taylor \& }
$$

\section{曲 Published online: 31 Oct 2013.}

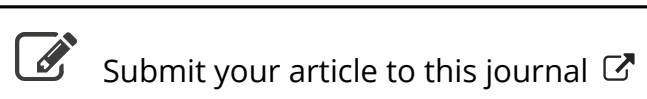

\section{Џll Article views: 7356}

View Crossmark data ¿

Citing articles: 37 View citing articles $[7$ 


\title{
Empowering young people and strengthening resilience: youth-centred participatory video as a tool for climate change adaptation and disaster risk reduction
}

\author{
Katharine Haynes $^{\mathrm{a} *}$ and Thomas M. Tanner ${ }^{\mathrm{b}}$ \\ ${ }^{a}$ Risk Frontiers, Macquarie University, Sydney 2109, Australia; ${ }^{b}$ Institute of Development Studies (IDS), \\ University of Sussex, Library Road, Brighton, UK
}

\begin{abstract}
Young people regularly face great hurdles to get their voices heard, while research and practice in the disaster and climate change community commonly represent young people as passive victims requiring protection. Consequently, their capacities to inform decision-making processes, communicate risks to their communities and take direct action to reduce risks have been neglected. This paper presents empirical data from participatory video (PV) methods with groups of young people in three communities in Eastern Samar, the Philippines. Producing these videos enabled groups to research, document and raise awareness of disaster risk, and use screening events to mobilise and advocate for risk reduction measures in their communities. The results suggest that the PV process was an effective tool for empowering young people to raise important issues with decision-makers and advocate change on behalf of their communities.
\end{abstract}

Keywords: children and young people; resilience; participatory video; disaster risk reduction; adaptation

Through video we may express ourselves, even if we are just children. (Child participant from Eastern Samar, the Philippines)

\section{Introduction}

This paper outlines an approach to building resilience to climate change and disasters at the community level, based on empowerment of young people and using participatory video (PV) tools as a means for youth-led research and advocacy. Dialogue and knowledge sharing are often constrained between those who face risks and those who control policy. Young people, who are frequently the most marginalised group, face significant hurdles to get their voices heard and valued. In these circumstances, $\mathrm{PV}$ is an effective way to include and reach powerless people and produce more equitable outcomes (Kindon 2003). Youth-centred PV approaches put one of the most marginalised groups at the centre of the advocacy process (Plush 2009). This research seeks firstly to validate if participation of children and young people in disaster risk reduction (DRR) helps

*Corresponding author. Email: haynes.katharine@gmail.com 
vulnerable communities reduce their disaster risks and secondly to examine the efficacy of PV as a means for engaging and empowering young people in the policy-making realm.

The paper first outlines the context for DRR and adaptation to climate change, development of youth-centred approaches to DRR and using PV as a research tool. It then presents the methodology utilised in this research including a multi-stage process of training, film-making and participatory screening workshops with communities and government officials. Results focus on efficacy of the action research for communication and raising awareness, advocacy, empowerment, risk reduction and adaptation. The paper concludes with a discussion of implications of this research for policy, practice and future research.

\section{Background}

\section{Disasters, climate change and young people's participation}

Tackling causes and impacts of climate change has emerged as a major global challenge of the twenty-first century. Given the potential for climate change to alter distribution and severity of extreme weather events, adaptation to climate change can draw much from policies and practices of DRR (Schipper and Pelling 2006). DRR represents a change in emphasis from humanitarian response and rehabilitation following disaster events towards disaster prevention and reduction of potential risks. This entails affording greater attention to social, economic and political factors that influence social vulnerability, rather than just the nature of the hazard and local environmental conditions (Wisner et al. 2004; Schipper and Pelling 2006). This situates DRR firmly within the broader development arena and disasters can be regarded as resulting from development failure, 'where the root causes of vulnerability merge with the origins of other development-related crises' (Gaillard 2010, 222).

Vulnerability to climate change and disasters has often been conceptualised as passivity and victimhood, particularly emerging from post-disaster studies that identify particularly vulnerable groups (Cannon 2008). This conceptualisation is common in literature linking children with climate change and disasters (Tanner 2010). However, a growing body of empirical research and practice is emerging that counters this vulnerability narrative, instead emphasising young people's capacities to influence and participate directly in efforts to learn about, prevent, prepare for, cope with and adapt to climate change and extreme events (Peek 2008; Mitchell et al. 2008; Tanner et al. 2009; Haynes, Lassa, and Towers 2010; Walker et al. 2012). Young people's participation in DRR and adaptation may therefore be conceptualised in multiple modes (Tanner 2010), including

- contextualising knowledge, using analytical tools and prioritising actions;

- advocacy and mobilisation, building coalitions with parents, community members and other stakeholders;

- conception, design and implementation of projects that tackle climate and disaster risks pertinent to children's lives;

- communicating risks, sharing and contextualising knowledge, building credibility and trust and persuading others to take action.

The emergence of youth-centred approaches to DRR and climate change adaptation has drawn heavily from theory and practice around children's participation (Hart 1997; Francis and Lorenzo 2002; Hill et al. 2004; Sinclair 2004). Many early models of youth participation were both functional and universal, negating the socially and culturally constructed nature of such processes (Shier 2001; Lansdown 2006). In contrast, the nature and mode of participation are usually influenced by the point and scale of entry, community and institutional dynamics, livelihood strategies and living standards, and cultural factors (Tanner 2010). 


\section{$P V:$ theory and practice}

Despite need to promote the voices of young people in policy debates on climate change and risk reduction, evaluation of methods for doing so are not well developed. PV was chosen here for various reasons. Firstly, it enabled young people to be in control of the process (Waite and Conn 2011). Secondly, it created an interactive research environment between young people, their community and researchers. This allowed issues and their causes, consequences and solutions to be grounded in how the youth and community saw them (Kindon 2003; Sandercock and Attili 2010; Garrett 2011). Lastly, it was hoped that the iterative process of filming, editing and screening would be an effective driver for social change (Kindon 2003; Sandercock and Attili 2010).

The first documented use of PV was in the late 1960s, when it was used to facilitate dialogue between residents of Fogo Island, Canada, and government officials. Crucially, the film-making process rather than the film itself acted as a means for social change (Weisner 1992; Sandercock and Attili 2010; Waite and Conn 2011). Among the social sciences, geographers have been generally slower to utilise PV, instead preferring photographs, photo diaries and verbal records (Kindon 2003; Hadfield and Haw 2011). In contrast, the method has been used extensively within the development field (often termed 'community video') since the mid-1970s (Kindon 2003; Mhando 2005). Examples of youth-centred PV have become more common in recent times, including some use in DRR and climate change contexts (Khamis, Plush, and Sepulveda Zelaya 2009; Plush 2009, 2012; Waite and Conn 2011; Blazek and Hraňová 2012).

To date the majority of this work, like that of PV in general, is from developing countries. Examples of youth-centred PV research examining climate change and DRR are rarer still. Plush (2012) provides a good overview of recent work in Vietnam and Nepal where youthcentred PV has been used within development programmes related to climate change and disasters. Handing the camera over allows participants the opportunity to record what they see and how they see it more freely (Garrett 2011; Sandercock and Attili 2010). It can diminish the hierarchical relationship between the researcher and the researched, 'offering a feminist practice of "looking alongside" rather than "looking at" research subjects' (Kindon 2003, 143). The result can be knowledge produced by and for the research participants and their community (Pink 2001). PV can also aid communication as it bypasses the barriers of literacy, allowing messages to be sent and received without writing or reading (Okahashi 2000).

Lunch and Lunch $(2006,10)$ argue that PV is relatively easy and 'is a great way of bringing people together to explore issues, voice concerns or simply to be creative and tell stories'. However, the approach goes beyond rich ethnography, community engagement and helping people communicate. Its popularity within the field of development is particularly due to its ability to provide a voice to the powerless and promote more equitable outcomes through use in the process of research, consultation, advocacy, community mobilisation and policy dialogue (Kindon 2003, 143; Garrett 2011; Sandercock and Attili 2010). Others have noted its potential to empower those who previously had no control over the media or what was reported about them (Mhando 2005) and its ability to increase self-esteem and community connection (Okahashi 2000).

Nevertheless, debates about the capacity of PV, and participatory research in general, to capture 'truths' suggest that these methods are prone to the same biases and subjectivity of other research methods (Garrett 2011; Sandercock and Attili 2010; Waite and Conn 2011). A potential problem is that researchers may be 'invisible' in the final product, which may not 'acknowledge the influence of the researcher, or encourage their self-reflexivity' (Kindon 2003, 146). Indeed, as noted by Waite and Conn (2011), topics or focus of participatory films may actually be co-determined by participants and researchers. Improved understanding and 
awareness of processes of participant motivation and selection are therefore required (Blazek and Hraňová 2012). Additionally, levels of independence offered to participants in terms of what and how they choose to film must be acknowledged and reflected upon within the research process and, if possible, the film itself.

Other criticisms relate to the assumption that PV processes break down power barriers. Critics note that in many situations power imbalances associated with race, gender, education and age remain. Walsh (2012), for example, questions whether we can be sure that participants do not simply enact what they think researchers expect. Further dangers of the PV process lie in presuming that the method naturally leads to empowerment and for presuming disempowerment in the first place (Shaw 2012). Regarding the tools as empowering in themselves obscures the complex social and political context within which the process takes place (Shaw 2012; Walsh 2012).

The research presented here explored some of these issues. The choice of PV as a method to some extent reflected its efficacy in telling stories and bringing people together (Lunch and Lunch 2006). It was also informed by related work in Nepal that used PV to influence local action and policy on DRR and climate change adaptation (Khamis, Plush, and Sepulveda Zelaya 2009; Plush 2009; Plush 2012).

\section{Research aim}

This action research project aimed to understand if PV was an effective process through which groups of young people could gain knowledge about disaster and climate change issues; research and learn about global/local causes and solutions; gain video documentary skills; and engage with stakeholders in order to advocate for adaptation and DRR programming. This notion of participatory documentary film-making puts young people in a 'video-active context' highlighting behaviour and observation in front of and behind the camera (Shrum, Duque, and Brown 2005). It also emphasised the importance of iterative cycles of film-making and review in generating ideas and debates (Kindon 2003).

The research examined the efficacy of PV as a tool for empowering young people living in disaster-prone communities through examination of the following research questions:

- Can PV be used to enable young people in vulnerable communities to influence and improve DRR policy and action?

- How can these processes increase learning and knowledge communication between vulnerable groups?

The final films produced through the process aimed to facilitate dialogue and advocacy between local communities and their government officials, and assist with advocacy on youth-centred approaches at international climate change and DRR meetings.

\section{Fieldwork locations}

The Philippines is the fourth most disaster-prone country in the world, according to the International Red Cross/Red Crescent Societies. Forty per cent of the total population of 92 million are under the age of 18 (National Statistics Office 2012). The case study locations were Barangay (a term used to describe the smallest administrative division in the Philippines, usually a village) within the municipalities of Llorente, Oras and Salcedo within the province of Eastern Samar (Figure 1). The province's population is approximately 400,000. The majority of households fall below the poverty threshold, with farming and fishing the dominant livelihoods, with some also engaged in copra (coconut) production and chromite mining. 


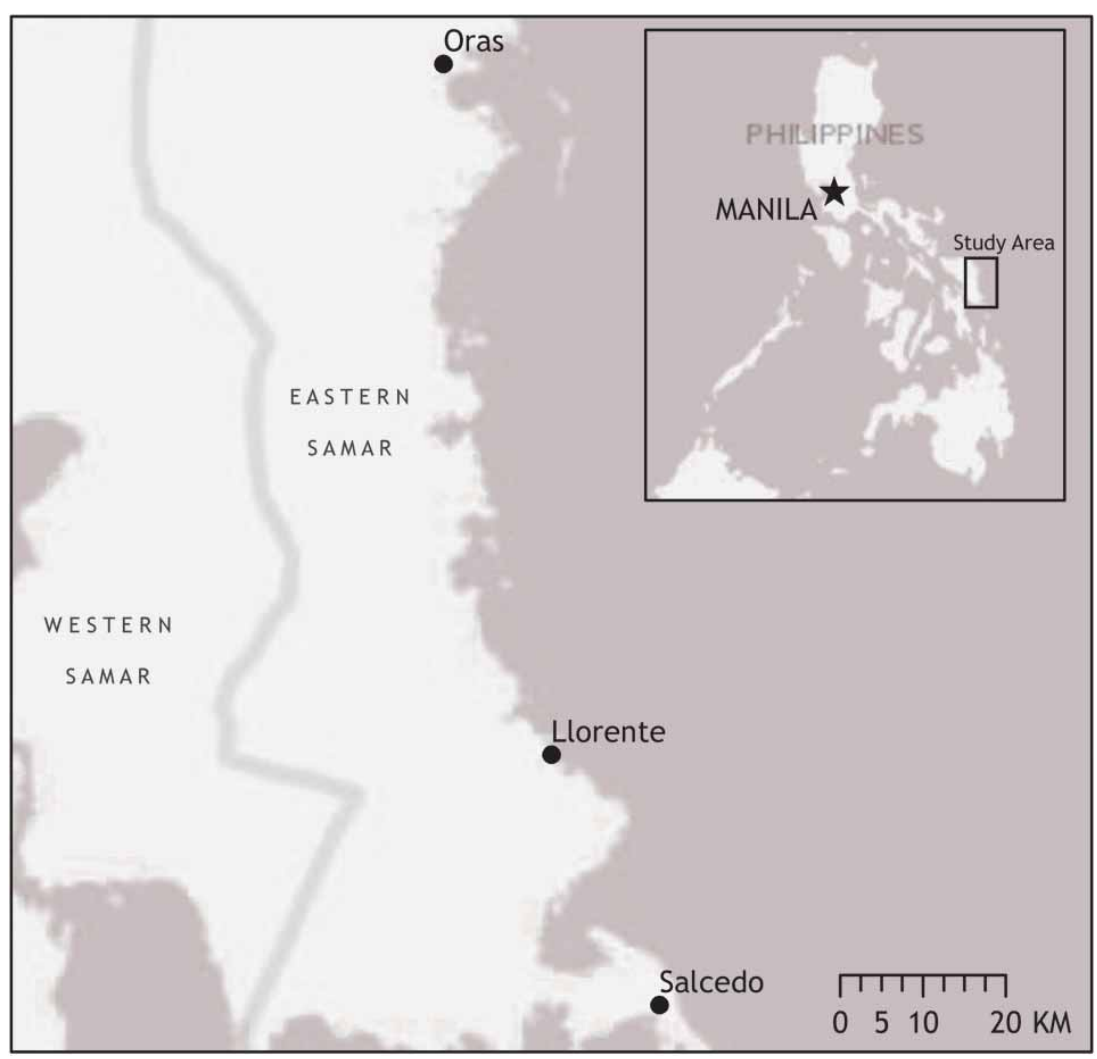

Figure 1. Case study locations, Eastern Samar Province, Philippines.

Eastern Samar is one of the most disaster affected areas in the country, exposed to high rainfall and frequent typhoons which typically track westwards across the Philippines, as well as storm surge and tsunami risks. It also lies between two major faults, the Philippine trench and the Negros trench, making earthquakes a common occurrence. The heavy rainfall and earthquakes cause frequent landslides and floods, which often isolate affected villages.

\section{Methodology}

The research project was partnered by Plan International, a child- and youth-focused development NGO. Plan Philippines began implementing its disaster reduction programme in 2006 and this research builds upon a relationship between Plan staff and authors of this paper. Plan staff provided field facilitation and introductions, through which a team of PV film experts and local and international researchers accessed young people in the case study locations. Research was financed through external support and in-kind staff contributions from Plan. As such, agreement among partners and the research process was designed to avoid biases and operate as an independent project rather than a consultancy assignment for Plan.

Groups were formed voluntarily by the children themselves, drawing on Plan's existing connections within communities. No payment was offered for their time; however, transport, food and all costs associated with making the films were covered. The young people were encouraged to form gender-balanced groups of ideally eight. The result was one group from each village with 
children aged 13-21. The group was gender balanced in Salcedo, but contained more girls than boys in Llorente and Oras.

Research was carried out in two stages between March and September 2009. First, youth attended participatory workshops run by the PV consultant and Plan staff with expertise in disasters and climate change. These trained young people on the concepts of DRR and climate change adaptation, the technical procedures of video production and its potential role as advocate for change.

Once young people had identified priority issues for investigation within their communities they debated the topic with other youth and adults from their communities. These ideas were then drawn up into storyboards and filming schedules. Feedback from Plan staff, PV consultants and researchers was provided to ensure storyboards were scientifically accurate and to offer advice on how the filming of topics could be improved. Young people were free to accept or reject these ideas and were encouraged to research their ideas further through interviews with officials, parents and community leaders, plus internet and book research. They conducted filming in their own time with assistance from local Plan staff, PV consultants and researchers when needed. The young people were, therefore, engaged in an iterative process of learning and filming, while the research team and partners guided with a practice of 'looking alongside' as advocated by Kindon (2003). They were also involved in the rough editing process of their films; however, final editing of films and incorporation of subtitles were completed by PV consultants in cooperation with Plan staff in Manila. Only one young representative from the three teams was present for the final edit due to financial constraints. Further reflections on the participatory nature of this process are provided in the penultimate section of the paper.

As a second stage, films were screened at three different scales. First, within each community, a screening and workshop were facilitated enabling the young people and adults to discuss issues raised by the films and possible solutions. Roughly 40 participants attended, including: filmmakers, Barangay officials, a selection of adults and young people residing in the community, Plan staff and researchers. These embedded the process as a project which had been conducted by the children for their community (Pink 2001). Participants at community workshops agreed on priority actions locally, while also identifying policy issues that would be taken as advocacy messages to video screening workshops with local government officials held at municipal and then provincial levels. The municipal screenings were attended by the film-makers, 2-3 Barangay officials, 6-10 municipal government officers, 1 or 2 teachers, Plan staff and researchers. At the provincial level, all three groups of film-makers, Barangay representatives, Plan staff and researchers met with provincial government officials. However, film-makers led the workshop and, unless asked to participate by the children, all other participants were passive.

The format of workshops was decided on jointly by the young people, researchers and Plan staff. The multi-scale advocacy process enabled discussion and decision-making about what problems could be solved in the community and which issues needed to be dealt with at the provincial and municipal level. While adults at community workshops were free to discuss and propose their ideas to film-makers, ultimately the decision on what advocacy messages would be presented to government officials was up to the young people. Therefore, although the multi-scale screenings were designed to gather community input and generate collaboration between young people and adults, ultimately the young people remained in control throughout the process.

Two key ethical and child protection issues were addressed. Firstly, to manage young people's expectations to ensure they would not be disappointed if their calls for action were not met. Briefings before and after the workshops discussed likely realistic outcomes given the wider social and political constraints, ensuring young people understood it was a long-term process and to concentrate on positive outcomes. Secondly, safety of young people while conducting filming and following the screenings when messages were released to the community. This was especially 
important for youth documenting and interviewing those engaged in illegal logging and mining activities. The groups conducted sensitive parts of filming while chaperoned by Plan field representatives who monitored schedules.

Filming, screening and workshop process was assessed through an action research, mixed methods approach, involving: participant observation of young people; participatory workshops undertaken as part of the screening process (involving young people, community and decisionmakers); informal focus groups with youth before and after the filming process and each workshop; and also a brief questionnaire undertaken by community members and decision-makers before and after the screening workshops. Information was recorded through use of a digital voice recorder, note taking and through collection and photography of group work notes.

Participant observations and focus groups during training and filming processes allowed researchers and Plan staff to determine the influence of the process on youth. Changes in views, knowledge and confidence were noted. It also enabled continual evaluation of the process and adapted to their changing needs.

Outline for each workshop:

- preparation/focus group session with youth, researchers and Plan staff to discuss upcoming workshop and what they hoped to achieve;

- introductions and background to the project and workshop aims;

- open questionnaire completed by community and decision-makers to gather baseline views and understandings around hazards and risks facing communities;

- participatory discussion on hazards and risks faced by communities and underlying causes, enabling in-depth exploration of baseline views and knowledge;

- synopsis of films by youth;

- film screening;

- small group work to discuss issues raised and questions for youth/decision-makers;

- questions from community members/decision-makers to young people;

- brief questionnaire completed by community and decision-makers involving same questions as pre-film questionnaire, enabling comparison with pre-film knowledge and views;

- repeat discussion on hazards and risks faced by community and underlying causes, allowing in-depth exploration of how and why the film had changed views;

- questions and calls for action from young people for assistance from community and/or decision-makers;

- discussion of how calls for action from young people could be addressed;

- feedback/focus group session with youth, researchers and Plan staff to debrief and discuss outcomes and plan next steps of action.

\section{Young people's research findings: PV process and output}

In all cases the groups chose the impact of flooding as their main topic. Plan and the funding agency Forces of Nature were keen to ensure that films clearly covered issues of climate change and disasters. However, within these parameters youth were free to cover any issues they felt were important within their communities. Flooding (from rainfall and cyclonic storm surge) is one of the most common disasters in Eastern Samar and something the young people had all experienced. The potential future link between increased flooding due to climate change was also discussed during the training process. It is therefore unsurprising that all youth selected flooding as the main topic for their films. Although all three films were flood related, each group explored differing social and political factors that contributed to their vulnerability to flooding. Film storylines are described below. 


\section{Chromite mining: the pock-marked face of Caga-ut}

Film-makers discover impacts of chromite mining and deforestation are the underlying drivers of vulnerability to extreme rainfall events that cause flooding and contamination in their village Caga-ut, Salcedo, Eastern Samar. Community members describe recent flooding and increased flood risk since the expansion of mining in their community. Other dangers, including skin disease, loss of marine and riverine biodiversity, mosquitoes breeding in water-filled mining pits and danger from falling in old mining pits, are discussed. The film reveals chromite mining is a divisive issue in the community between those who are benefiting from the mining, and those who are exposed to risks but receive no benefits. Film-makers organise and film a community meeting to openly discuss issues. Following this, officials ban mining close to the village and pledge to replant trees and fill in old mining pits.

\section{Flood vulnerability from illegal quarrying and deforestation - Barobo: the sinking Barangay}

The film investigates increasing flood risks faced by Barangay Barobo, Llorente, Eastern Samar. Film-makers first demonstrate impact of flooding on their education, the community's assets and local livelihoods through use of photographic stills and interviews. They then investigate causes, determining that illegal logging, slash-and-burn practices and sand mining along the river bank are significant factors. They interview a logger and slash-and-burn farmer, distorting images to ensure identities remain anonymous. Young people also note the geographic location of their village next to the river is a factor increasing their exposure.

Young people call a meeting with their Barangay leaders to discuss their findings. An interview with the Vice-Mayor of the district reveals that local government is aware of links between logging and increasing flood risks. The Vice-Mayor notes that policy has been initiated to limit logging in certain areas, especially within the upstream Barangays. Young people conclude the film stating that although the government is initiating some programmes not enough is being done to limit the logging, slash and burn and sand mining. The young people want these practices banned, alternative livelihoods established and a municipality-wide tree-planting scheme initiated.

\section{Flooding in Oras - flood: a menace to education}

The film focuses on the impact of flooding on education of young people in Barangay Cadi-an, Oras. Youth show the impact of a recent flood on their school building, furniture and books, which resulted in suspension of classes for weeks. An interview with a local scientist points to climate change as a cause of the flooding. However, through a risk map, young people demonstrate that location of the Barangay, and in particular the school, within a bend in the river greatly increases their exposure. Short of relocating the school, youth identify risk reduction options including elevating the school, storing the most vulnerable school equipment off-site and installing elevated cabinets to keep school items out of flood waters. The Barangay council state funding is a barrier to implementing all these measures, but decides to invest in elevated cabinets. The council also decides to send a proposal to the Department of Education and the office of the Mayor for funding to construct a two-storey classroom.

\section{Young people's views on what they hoped to achieve}

At the start of the training workshop, some apprehension was expressed by young people with regard to making the film and communicating this to policy-makers and other community 
members. Many young people expected to be discredited by the audience or even by their parents. However, as the workshop training progressed, the young participants began to gain confidence and recognised their unique abilities as risk communicators. In discussions following the training process, the majority of film-makers' feedback was centred on the need for their communication and awareness-raising in the community and at higher levels of government. All hoped their films would deliver these important messages and bring about change:

Our inspiration in making the film is our fellow youth. We are certain that we are not the only ones experiencing flood. More importantly, the flood negatively affects our schooling. We believe and claim that children hold the future, so let us lessen the risks in our Barangay. (Llorente, filmmaker, female)

We got inspired by the flood, how it affected our learning and its effect on the economic life of the people. We are familiar that after the flood most of us here had tough times. This is our way of helping the Barangay particularly to prevent the same from happening again. (Llorente, filmmaker, male)

We were able to discover our skills, develop our talent because we never expected we could make such a film as well as helping the Barangay. (Oras, film-maker, female)

I don't want this to end only after the film. We want them to adopt those practices which would benefit the community. (Oras, film-maker, male)

A number of young people discussed how meetings and interviews they had conducted with government officials and other stakeholders during film-making had been a valuable experience. They noted this was not a common exercise for youth and they appreciated the opportunity to broaden their experience and confidence.

\section{Advocacy and the impact of multi-scale screenings}

Screenings were attended by the film-makers, Barangay officials, a selection of adults and young people residing in the community, Plan staff, researchers and 6-10 municipal government officers. Approximately 40 people attended each workshop. Results of questionnaires and discussions before and after screenings reflect both differences in perceptions of the causes and consequences of the disasters, and how those perceptions changed following the film screening. Participants in all communities stated they had predominantly experienced storms and flooding in their community followed by earthquakes. Participants in Salcedo also listed landslides. Prior to screening, the majority of participants in Salcedo and Llorente noted human causes (illegal logging and mining) underlying the disasters they had experienced. In contrast, in Oras natural causes (typhoons) were cited as the dominant cause by all adults and the majority of the youth, although land clearing was also discussed. In Salcedo and Oras, a few of the non-filmmaking youth discussed impacts of the location of the Barangay, hunger, poverty and drug dealing on disaster risks. No adults or decision-makers noted these wider social vulnerabilities prior to watching the films. Views on who was responsible to take action to reduce disaster risks were split between Barangay officials, local and national governments and the community. Those in Oras predominantly listed decision-makers while those in Salcedo and Llorente listed everybody as being jointly responsible.

Following the film screening in Salcedo, roughly half the participants stated they had learnt about the dangers of chromite mining. Participants also stated they had learnt about the relationship between mining and an increased risk of flooding and increased vulnerability of the community to potential climate change impacts in general. After the screening, four adults now listed chromite mining and one listed poverty as the cause of disaster risks, where none had done so 
prior to the screening. There was also an increase in youth and decision-makers who named chromite mining as a cause of disasters.

The municipal decision-makers largely agreed to the proposed solutions in the film. They stated campaigns, networking with concerned agencies, alternative livelihoods and provincial ordinances regulating or prohibiting chromite mining must be initiated. Some also suggested need for full consultation in the Barangay to decide how these problems will be resolved.

Following the film screening in Oras, the majority of adults and youth stated they had learnt about the danger flooding posed to young people's education. A few of the adults and youth suggested the film could have been improved with more details of other communities who needed help and more focus on the aftermath of a disaster:

We were able to see the effects of the problem that were caused by people. It also shows what the necessary actions for the community were. (Adult workshop participant, Oras, female)

Post-screening responses on causes of disasters in Oras were similar to pre-screening responses, with natural causes (typhoon) remaining dominant. Land clearing was also still seen as a major cause. However, two adults now also listed the geographical location of the Barangay as a cause. During the film-making process Barangay officials and parents-teachers association had already agreed to install elevated cabinets within the school and petition the municipal government for funding to build a second storey. Municipal government officials agreed to consider the Barangay's application for a second storey on their school.

In Llorente, after watching the film the majority of participants stated they had gained new information about the human causes of disaster risk in the Barangay and how these can be reduced. Both adults and decision-makers listed logging as a cause before the screening but afterwards were now more specific and also listed kaingin (forest burning) as a form of land clearing:

First, the message is to minimize illegal logging, quarrying, and kaingin. Second, to awaken the residents in Barobo that the Barangay is in danger already. We should stop illegal activities otherwise we might regret later. (Adult workshop participant, Llorente, female)

As children, the effect of the film on us is to plant trees, stop illegal logging and to report sand quarrying. (Youth workshop participant, Llorente, male)

The community and young people called for stronger action and enforcement on illegal logging and mining activities. During the community workshop participants agreed that they wanted Barangay officials to establish an organisation to support and implement risk reduction measures such as tree planting and provide alternative livelihood to illegal loggers and kaingin farmers. In addition, they wanted a system for quick reporting from the Barangay to higher authorities regarding environmental violations. These calls for action were discussed with the municipal government who replied that they are already initiating action on logging in upstream Barangays. However, no further action was agreed upon during the municipal meeting in regard to further policy or disciplinary actions on those who violate laws.

\section{The provincial government screening in Eastern Samar}

The provincial level screening was attended by nine representatives from the Department of Education, Philippine Information Agency, the Provincial Planning and Development Office of the provincial government and the Provincial Board of the province. The Governor of Eastern Samar did not attend the meeting despite agreeing to. The majority of provincial decisionmakers had experienced flooding and typhoons followed by earthquakes. The majority attributed the cause of these disasters to illegal logging/slash and burn, and some to improper waste disposal. 
The majority stated that those responsible for taking action were the local leaders and public officials, but made note of the communities' responsibilities.

Following the screening, the provincial decision-makers stated they had learnt about impacts of illegal mining and logging and also that youth/children can be agents of change. They also listed a number of other issues for film-making including: funding alternative livelihoods, solid waste management, quarrying, corruption, distorted educational system, rising criminality, illegal gambling, malnourishment of children, and child and maternal mortality. Following screening, most again identified causal factors of illegal logging/slash and burn. However, mining and the illegal extraction of gravel and sand were now listed as the second highest cause. Participants said they could help young people with their goals by supporting their plans but also through assisting with information dissemination to other schools within the province and to get their message to the Governor.

\section{Empowerment, advocacy and impact of the PV process}

A key benefit for young people who participated was their increased awareness and knowledge of disaster risks in their communities, and their greater confidence to question community members and decision-makers. Adults were surprised by the level of knowledge displayed by the youth and their emphasis on the underlying social causes of disaster. A few community members also noted how the young people, with aid of the videos, were better able to communicate the community's message to decision-makers than adults would be. Adults were felt to be too restricted and even if the film portrayed an honest account it would be interpreted as biased:

The adults are not free in making films ... the children's style is emotional, credible, reliable and encouraging. (Adult workshop participant, Llorente, female)

It shows the great contribution of the youth. They have goals to carry out for the benefit of the community. They help their family to prevent the bad happenings of calamity in the barrio. (Adult workshop participant, Oras, male)

Importantly, during workshops it was youth, much more than the adults, who continually identified and discussed the importance of the underlying social causes of disasters. In particular, other youth who had not been part of the film-making process and therefore had not been influenced by training and awareness-raising emphasised hunger, poverty and drug dealing in discussions and feedback forms. Such social construction shows a multifaceted understanding of vulnerability far beyond any of the adults, including the government officials. This finding demonstrates the unique perspectives that young people can bring to the adaptation and DRR process (Tanner 2010).

This social vulnerability perspective and understanding was communicated through the films and subsequent discussions to adult community members. Following film screenings, the majority of community participants expressed that the video documentaries showed the realities and problems confronted by communities. Many stated they had been unaware of the extent and social causes of these problems. The majority of participants agreed with content of the films: problems presented; causes identified and solutions proposed. All groups reported they had learnt new information from young people and the films, confirming that youth are highly capable and effective local communicators.

The PV process led to a number of positive outcomes for communities. The Caga-ut team's investigation and filming process influenced members of the village council to compel miners to fill in old mining pits and to replant trees in areas where chromite has been extracted. In Cadi-an, the film documented how the young people's investigation and advocacy during filming actually 
motivated the village leaders and school council to support the school to install elevated cabinets to keep learning materials above potential flood waters. Following the community screening process, residents stated they would replant trees and bamboo near the river bank as a flood control measure. Following the film screening in Barobo, the community called for Barangay leaders to establish a group to initiate tree planting and alternative livelihood for loggers and kaingin farmers. In addition, they wanted a system for quick reporting from the Barangay to higher authorities regarding environmental violations.

The young people involved were actively engaged in the local actions stimulated by the research and video-making process. These included tree-planting campaigns, discussions with teachers on DRR measures in the school and creating dialogue with community leaders about livelihood activities that heightened risks, such as mining. Crucially however, the PV and workshop process provided a mechanism to enable young people to communicate and advocate their case to local government decision-makers. The municipal officials noted, however, that parents, teachers and other adult community members should also be involved in the campaign. Absence of the Governor of Eastern Samar at the final screening in the Philippines highlighted difficulties in gaining government participation on controversial or sensitive issues.

In Salcedo, two municipal decision-makers stated they would help by trying to push through DRR legislation. In Oras, participants said they could help young people through advocacy and supporting their activities to make school equipment safer from flood water, including considering the Barangay's application for a second storey on their school. However, in Llorente the municipal decision-makers told youth they were already initiating action on logging in upstream Barangays and that no further action was agreed upon due to links to livelihood security. Provincial decision-makers said they could help young people's goals by supporting their plans and assisting with information dissemination to other schools within the province and getting their message to the Governor.

While demonstrating an ability to amplify young people's voices, these examples also highlight the importance of power and politics in determining the vulnerability contexts in which disasters either unfold or are prevented (Gaillard 2010). Indeed, measure of success may be seen by some as the level of social change initiated by the process, reflecting the wider critique of participation in failing to challenge existing power relations (Hickey and Mohan 2005). For example, while discussions at the local level led to a community moratorium on mining in the immediate vicinity of Barangay Caga-ut, political support for mining interests meant that the benefits of the PV process were not seen at the municipal or provincial level.

\section{Reflections on the PV process}

Although designed to be youth led, there was more assistance from adults with script development and video editing than initially planned. The majority of feedback was to ensure accuracy with the science and concepts young people were explaining. An important part of this process was awareness and knowledge of disaster and climate change issues gained by young people and communities. In any case, young people were receptive to suggestions for how they could improve their films. They wanted to learn about climate change and disasters and how risks could be reduced in order to make powerful films that would be successful in generating policy change. Importantly young people were free to accept or reject advice given and no changes were made against their wishes. As noted by Mhando (2005) documentary video production is often viewed as a creative treatment of reality in order to produce an entertaining film, while PV production is much more about the process rather than the final product. In this case, the method became more of a balance between the process of PV-making and the needs of young people, partners and funders to produce films for advocacy. The process was therefore 
more of a collaboration between young people and adults, albeit one that was more youth led than the 'program with shared decision making' described by rung 6 of Hart's ladder of child participation (1997).

While the focus on disasters was influenced by funding sources, need for scientifically accurate films was crucial to the aims of international partners to show the documentaries at international climate change forums, including the Conference of Parties in Copenhagen, December 2009. During the process, the young people noted that ideally they would make different films for different audiences, including versions for local and national audiences. Young people used Eastern Samar dialect Waray-Waray in their film rather than the national language of Tagalog. Although the majority of Filipinos are fluent in Tagalog, use of local language made the film more 'local' and therefore relevant for the community and decision-makers. This means that two sets of subtitles are needed in order for national and international advocacy. Unfortunately, time frame and resources allocated to the project meant that only one film per group could be made. Transparency was crucial, and Plan explained where they intended to show films and, although children discussed issues above, they were happy for their films to be presented nationally and internationally.

Additionally, the iterative process of filming, discussion and editing is not presented in the films. Films were created for the local and regional level advocacy process where the children, Plan and researchers were all present to provide an introduction. When films are viewed in isolation on YouTube, this context is hidden. For future films, it may be instructive to include a short introduction by participants outlining the process and aims of the project. One option is creation of an overview video that presents highlights from films but also provides explanation of the PV process for an international audience (see Plush 2009).

\section{Conclusions on the use of PV for DRR and adaptation}

In addition to revealing insights for the role of PV methods in promoting empowerment and advocating for risk reduction, the research illustrates the socially constructed nature of climate change and disaster risk (Wisner et al. 2004; Gaillard 2010). Climate change is identified as a cause of a rising hazard burden, for example, through more intense rainfall leading to greater floods. However, young people's investigation and action presented here demonstrate how risks are a result of exposure (such as coastal and riverbank village location) and sensitivity (e.g. through climate-sensitive livelihood activities, poor infrastructure or malnutrition levels). Each film reflects an understanding of these social and political root causes of vulnerability that contribute to flooding, be it the position of the Barangay or illegal quarrying and deforestation. Through this vulnerability emphasis, participants have developed their capacities to reduce risk based not only on physical aspects of the hazard, but also on the human causes of risk that require behavioural and policy change (Chawla and Johnson 2004; Peek 2008).

Despite the successes of this project, the PV process must be recognised as a long-term effort, in terms of both empowerment and risk reduction impact (Waite and Conn 2011). Although funding was relatively short term, the team aimed for the project to continue beyond the life of this project and cameras were left with communities, under the responsibility of the local Plan office. A number of follow-on activities and outcomes have already been conducted, including further screenings to communities and decision-makers, the passing on of film-making knowledge to other young people and further use of PV tools.

In addition to young people's groups, the project also contributed to building the capacity of Plan local staff and media partners to undertake PV to support youth-centred DRR. For example, Plan Philippines has already supported young people to produce a new health/epidemic prevention video. The PV method has also been replicated in other countries, with Plan Indonesia 
utilising it as a tool for a youth-led evaluation of Plan's Padang earthquake response in October 2009. Furthermore, the films have the ability to transcend scales and, in addition to in-country advocacy, have been screened at the Film Festival at the 2009 UNFCCC conference in Copenhagen, the International Handprint workshop in Sweden, SIDA's DRR \& Human Rights Conference, ADPC's 2009 DRR Practitioners Event and other conferences and training events.

A final note of caution relates to the funders and NGO partners who may have very clear expectations of the risk reduction and adaptation messages they want the films to convey. The end result will often differ to that which was envisaged by these partners, as the participants learn, question and take ownership of the project. Although adult guidance and feedback are essential to the process, young people must remain free to investigate and communicate the messages they feel are important. While films may not end up having obvious climate change and disaster themes, the specific local knowledge on issues of vulnerability that young people uncover - be it rising sea levels or increasing alcohol and drug use - will have important implications for the community's ability to cope and adapt to current and future environmental change.

\section{Acknowledgements}

We would like to thank all of the young people, parents and participants who participated in this research. The research would not have been possible without Ladylyn Lim-Mangada and researchers from the University of the Philippines, and staff from Plan UK, Plan Indonesia and Plan Philippines. Thanks to Tamara Plush, who provided assistance and guidance throughout the project. This research was funded by Force of Nature Foundation, Plan International, Risk Frontiers and the UK Economic and Social Research Council (ESRC grant no. RES-061-25-0148).

\section{References}

Blazek, M., and P. Hraňová. 2012. "Emerging Relationships and Diverse Motivations and Benefits in Participatory Video with Young People." Children's Geographies 10 (2): 151-168.

Cannon, T. 2008. Reducing People's Vulnerability to Natural Hazards, UNU-WIDER Research Paper No. 2008/34. Bonn: UNU.

Chawla, L., and Johnson, V. 2004. "Not for Children only: Lessons Learnt from Young People's Participation." Participatory Learning and Action, 50 (October): 63-72.

Francis, M., and R. Lorenzo. 2002. "Seven Realms of Children's Participation." Journal of Environmental Psychology 22 (1-2): 157-169.

Gaillard, J. C. 2010. "Vulnerability, Capacity and Resilience: Perspectives for Climate and Development Policy." Journal of International Development 22 (2): 218-232.

Garrett, B. L. 2011. "Videographic Geographies: Using Digital Video for Geographic Research." Progress in Human Geography 35 (4): 521-541.

Hadfield, M., and K. Haw. 2011. Video in Social Science Research: Forms \& Functions, 196. London: Routledge.

Hart, R. A. 1997. Children's Participation: The Theory and Practice of Involving Young Citizens in Community Development and Environmental Care, 208. London: Earthscan.

Haynes, K., J. Lassa, and B. Towers. 2010. The Influence of Risk, Gender and Religion on Child-Centred Disaster Risk Reduction. Children in a Changing Climate Working Paper 2. Brighton: Institute of Development Studies.

Hickey, S., and G. Mohan. 2005. "Relocating Participation within a Radical Politics of Development." Development and Change 36 (2): 237-262.

Hill, M., J. Davis, A. Prout, and K. Tisdall. 2004. "Moving the Participation Agenda Forward." Children and Society 18 (2): 77-96.

Khamis, M., T. Plush, and C. Sepulveda Zelaya. 2009. "Women's Rights in Climate Change: Using Video as a Tool for Empowerment in Nepal." Gender \& Development 17 (1): 125-135.

Kindon, S. 2003. "Participatory Video in Geographic Research: A Feminist Practice of Looking?" Area 35 (2): $142-153$. 
Lansdown, G. 2006. "International Developments in Children's Participation: Lessons and Challenges." In Children, Young People and Social Inclusion: Participation for What? edited by K. Tisdall, J. Davis, A. Prout, and M. Hill, 256. Bristol: Policy Press.

Lunch, N., and C. Lunch. 2006. Insights into Participatory Video: A Handbook for the Field. Oxford: InsightShare.

Mhando, M. 2005. "Participatory Video Production in Tanzania: An Ideal or Wishful Thinking?" Tanzanet Journal 5 (1): 9-15.

Mitchell, T., K. Haynes, N. Hall, W. Choong, and K. Oven. 2008. "The Role of Children and Youth in Communicating Disaster Risk." Children Youth and Environment 18 (1): 254-279.

National Statistics Office. 2012. "The Age and Sex Structure of the Philippine Population: (From the 2010 Census)." Accessed August 13, 2013. http://www.census.gov.ph/content/age-and-sex-structure-philip pine-population-facts-2010-census

Okahashi, P. 2000. "The Potential of Participatory Video." Rehabilitation Review 11 (1): 1-4.

Peek, L. 2008. "Children and Disasters: Understanding Vulnerability, Developing Capacities, and Promoting Resilience." Children, Youth and Environments 18 (1): 1-29.

Pink, S. 2001. Doing Visual Ethnography, 240. London: Sage.

Plush, T. 2009. "Amplifying Children's Voices on Climate Change: The Role of Participatory Video." PLA Notes 60: 119-128.

Plush, T. 2012. "Fostering Social Change Through Participatory Video: A Conceptual Framework." In Handbook of Participatory Video, Chapter 4, edited by E.-J. Milne, Claudia Mitchell, and Naydene de Lange, 500. Plymouth: AltaMira Press.

Sandercock, L., and G. Attili. 2010. "Digital Ethnography as Planning Praxis: An Experiment with Film as Social Research, Community Engagement and Policy Dialogue." Planning Theory and Practice 11 (1): $23-45$.

Schipper, L., and M. Pelling. 2006. "Disaster Risk, Climate Change and International Development: Scope for, and Challenges to, Integration." Disasters 30 (1): 19-38.

Shaw, J. 2012. "Interrogating the Gap Between the Ideals and Practice Reality of Participatory Video." In Handbook of Participatory Video, Chapter 14, edited by E.-J. Milne, Claudia Mitchell, and Naydene de Lange, 500. Plymouth: AltaMira Press.

Shier, H. 2001. "Pathways to Participation: Openings, Opportunities and Obligations." Children \& Society 15 (2): $107-117$.

Shrum, W., R. Duque, and T. Brown. 2005. "Digital Video as Research Practice: Methodology for the Millennium.” Journal of Research Practice 1 (1): Article M4. Retrieved September 2013, from http:// jrp.icaap.org/index.php/jrp/article/view/6/12

Sinclair, R. 2004. "Participation in Practice: Making it Meaningful, Effective and Sustainable." Children \& Society 18 (2): 106-118.

Tanner, T. 2010. "Shifting the Narrative: Child-led Responses to Climate Change and Disasters in El Salvador and the Philippines." Children \& Society 24 (4): 339-351.

Tanner, T. M., M. Garcia, J. Lazcano, F. Molina, G. Molina, G. Rodríguez, B. Tribunalo, and F. Seballos. 2009. "Children's Participation in Community-based Disaster Risk Reduction and Adaptation to Climate Change." Participatory Learning and Action 60: 54-64.

Waite, L., and C. Conn. 2011. "Creating a Space for Young Women's Voices: Using 'Participatory Video Drama' in Uganda." Gender, Place and Culture: A Journal of Feminist Geography 18 (1): 115-135.

Walker, M., R. Whittle, W. Medd, K. Burningham, J. Moran-Ellis, and S. Tapsell. 2012. "II Came Up to Here': Learning from Children's Flood Narratives.” Children's Geographies 10 (2): 135-150.

Walsh, S. 2012. "Challenging Knowledge Production with Participatory Video." Chapter 15 in Handbook of Participatory Video, edited by E-J Milne, Claudia Mitchell, Naydene de Lange, 500. USA: AltaMira Press.

Weisner, D. 1992. "Media for the People: The Canadian Experiments with Film and Video in Community Development." American Review of Canadian Studies 2 (1): 65-75.

Wisner, B., P. Blaikie, T. Cannon, and I. Davis. 2004. At Risk: Natural Hazards, People's Vulnerability and Disasters, 284. London: Routledge. 